Review Article

\title{
Strategic nutrition: a vision for the twenty-first century
}

\author{
Norman J Temple* \\ Centre for Science, Athabasca University, Athabasca, Alberta T9S 3A3, Canada
}

Submitted 27 December 2013: Final revision received 2 December 2014: Accepted 9 December 2014: First published online 2 February 2015

\begin{abstract}
It is now widely accepted that poor nutrition plays a major role in the epidemic of various diseases, including obesity, type 2 diabetes and CVD. There has also been much research regarding the role of related factors such as advertising and food prices. Many intervention studies have been carried out where attempts have been made to persuade people to modify their behaviour, such as by making dietary changes, in order to enhance health (health promotion). There has also been much debate on the potential of government policy as a tool for achieving these goals. Various proposals have been made, such as a tax on sugary drinks, the redirection of food subsidies and how the salt content of food can be reduced. However, the great majority of previous papers have considered only single aspects of the topics discussed here. The present paper reviews strategies for improving public health, both health promotion interventions and the use of government policy approaches. Topics discussed include providing advice for the general population and the design of food guides and food labels. This leads to the conclusion that we need an overall strategy that integrates this diverse body of information and formulates a comprehensive action plan. I propose the term 'strategic nutrition'. The implementation of this plan opens up a path to a major advance in public health.
\end{abstract}

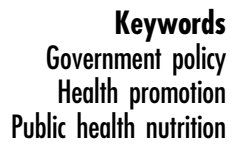

Government policy Public health nutrition
Over the past half century there have been many advances in all areas of nutrition, including diet in relation to disease. Based on this information public health nutrition has emerged as a crucially important field. Much important information has been discovered regarding the role of related factors such as advertising and food prices. There have been many intervention studies where attempts have been made to modify behaviour, such as making dietary changes, in order to enhance health. There has also been much debate on the potential of government policy as a tool for disease prevention. The present paper briefly reviews these topics and then integrates this information together. This leads to the general conclusion that we now have the capability to apply our current knowledge of nutrition in a strategic way. By this means, a major advance in public health can potentially be achieved.

\section{Dietary causes of major diseases and disorders}

\section{Obesity}

An epidemic of obesity started in the USA around 1980 and then spread to much of the world. Obesity is strongly associated with risk of type 2 diabetes, hypertension and cancer of the colon and breast.

Much evidence indicates that sugar plays an especially important role in the aetiology of obesity. Sugar may work synergistically with fat in this regard: sugar-fat mixtures, as in cakes and cookies, can be very tasty and appealing which therefore encourages overeating. Of particular importance, sugar-sweetened beverages (SSB) facilitate a raised energy intake and are associated with weight gain ${ }^{(1)}$.

There has been much interest in the possible relationship between dietary fat and obesity. Cohort studies have failed to detect a significant association between dietary fat and weight change ${ }^{(2,3)}$. However, many randomized controlled trials (RCT) have been carried out where one group of subjects was randomized to a fat-reduced diet but where weight loss was not an objective. Such studies mimic a real-world situation. A recent review reported that after a minimum of 26 weeks of follow-up, subjects consuming a fat-reduced diet had a statistically significant $1.6 \mathrm{~kg}$ lower weight (and a $0.3 \mathrm{~cm}$ lower waist circumference) than those eating a regular $\operatorname{diet}^{(3)}$.

Much research supports the concept that foods with a high energy density (i.e. a high content of energy per 
gram) lead to excess energy intake, weight gain and obesity $^{(4,5)}$. Because dietary fat provides more than twice as much energy per gram than either protein or carbohydrate, foods high in fat generally have a high energy density. By contrast, foods with a high content of fibre or water, such as fruit and vegetables, generally have a low energy density and lead to a reduced energy intake.

Another factor that may be contributing to the obesity epidemic is large portion sizes; these induce people to eat significantly more food ${ }^{(6,7)}$.

The various factors implicated in obesity are so pervasive that it is almost as if society had been carefully designed to create an epidemic of obesity. Consider the following:

- Everyone is continually exposed to foods with a high energy density and to SSB. Moreover, large portion sizes have become increasingly common.

- Foods with added sugar and fat have a high energy density and are cheap sources of food energy ${ }^{(8,9)}$. This exerts economic pressure on people, especially those with a low income, to buy foods that are more likely to induce obesity. Similarly, large portion sizes are also cheaper sources of food energy (measured as dollars per $1000 \mathrm{~kJ})^{(7)}$.

- The companies in the USA that sell unhealthy foods spend billions of dollars each year on advertising ${ }^{(10,11)}$. This massively outweighs the education directed at children regarding healthy eating. For example, for every dollar spent by the US Department of Agriculture promoting MyPlate (the new food guide), the fast-food industry spends well in excess of \$US 1000 on the advertising of relatively unhealthy foods.

- Thanks to labour-saving devices most people can carry out their everyday activities with almost no physical activity. Similarly, most children spend far more time in front of a television (TV) or computer than engaged in sports or walking ${ }^{(12)}$.

A consideration of the above factors, acting in concert, compels the conclusion that today's environment is obesogenic.

\section{Type 2 diabetes}

Type 2 diabetes has a devastating health impact. Cohort studies have consistently demonstrated that a relatively low intake of dietary fibre from cereals is associated with an increased risk of the disease ${ }^{(13)}$. This suggests that a diet rich in whole grains is protective against the development of diabetes.

Several RCT have reported that lifestyle intervention is able to much reduce the proportion of subjects with impaired glucose tolerance who progress to diabetes ${ }^{(14)}$. The intervention often includes a generally improved diet, such as an increased intake of dietary fibre, but the emphasis has been on weight loss. Exercise appears to have an even stronger protective effect than weight loss ${ }^{(13)}$.

Despite the success of the interventions, many of the subjects with impaired glucose tolerance go on to develop diabetes. Clearly, therefore, primary prevention is hugely preferable to secondary prevention. Accordingly, there is an urgent need for implementing lifestyle intervention programmes in obese people in the general population and others at elevated risk, especially in populations where the disease is common.

\section{CVD}

It is generally accepted that removing SFA from the diet and replacing them with PUFA helps prevent $\mathrm{CHD}^{(15,16)}$.

It should be noted that despite the widespread acceptance of this hypothesis of $\mathrm{CHD}$, there are notable inconsistencies in the supporting evidence ${ }^{(17)}$. Numerous RCT have been carried out in which dietary intake of SFA has been lowered while PUFA has been increased. These studies were mostly secondary prevention as the large majority of the subjects had pre-existing CVD. In a recent analysis of RCT Ramsden et al. ${ }^{(18)}$ argued that when SFA are replaced with $n$ - 6 PUFA, there is no decrease in the risk of CHD. They did, however, report that when SFA are replaced by a mixture of $n-3$ and $n-6$ PUFA, then a reduced risk of CVD is achieved. Another apparent flaw in the dietary fat hypothesis is that the intake of SFA appears to be unrelated to risk of $\mathrm{CHD}^{(19)}$. However, others have disputed the significance of these findings ${ }^{(20)}$. Despite these question marks, prudence suggests that we should advocate a reduced intake of SFA and their substitution by unsaturated fats, mainly PUFA (both $n-3$ and $n-6$ ).

An impressive body of evidence from cohort studies shows that people who consume fish regularly have a lower risk of CHD mortality $(\sim 20-38 \%$ lower $)$ than do people who seldom eat fish ${ }^{(21,22)}$. The active ingredient in fish is believed to be long-chain $n-3$ PUFA which are abundant in fatty fish, such as anchovies, herring, salmon (both farmed and wild), mackerel, sardines, trout and white tuna ${ }^{(22)}$. However, findings from RCT (mostly secondary prevention studies) have indicated a much weaker degree of reduction in risk of cardiac death (9\%) when subjects were given marine $n-3$ PUFA $^{(23)}$.

Trans-fatty acids are found in many processed foods, including cookies, cakes and crackers. These fats are linked to an increased risk of $\mathrm{CHD}^{(24)}$; it is estimated that they cause about 100000 deaths per annum from CVD in the USA ${ }^{(25)}$.

Hypertension is strongly associated with risk of both CHD and stroke. The excessive salt content found in the diets of almost everyone has been firmly established as causing an elevation in blood pressure. Conversely, a decrease in salt intake significantly lowers blood pressure, especially in persons with hypertension ${ }^{(26,27)}$. Cohort studies have reported a positive association between salt intake and risk of both CHD and stroke ${ }^{(26)}$. It has been estimated that a reduction of dietary sodium intake in the USA by $1200 \mathrm{mg} / \mathrm{d}$ would result in 44000 to 92000 fewer deaths annually ${ }^{(28)}$. It would also be expected to decrease the annual incidence of CHD by up to 110000 and stroke by as much as 40000 . 


\section{Foods and dietary components that affect risk of disease}

The evidence summarized above informs us that features of the diet closely linked to disease include trans-fatty acids, excess salt and a high energy density. The diet would be improved if it included more fish. We now examine several other aspects of the diet.

\section{Fruit and vegetables, whole grains, meat, sugar}

A generous intake of fruit and vegetables reduces the risk of cancer, although to a lesser degree than was commonly believed 10 or 20 years ago. Our most reliable evidence has come from cohort studies and these suggest that each extra $100 \mathrm{~g}$ of fruit and vegetables daily reduces risk by no more than $4 \%^{(29-31)}$. In the area of CHD, by contrast, we see clear evidence of risk reduction from the consumption of these foods ${ }^{(32)}$; a suboptimal intake causes about 100000 deaths from CVD each year in the USA ${ }^{(25)}$.

Whole grains are also protective against several diseases. The evidence from cohort studies indicates that persons who habitually consume a diet rich in these foods have a reduced risk of type 2 diabetes (see above), $\mathrm{CHD}^{(32)}$ and colon cancer ${ }^{(33)}$. In stark contrast, consumption of red meat and of processed meat is associated with increased risk of CVD, cancer and diabetes ${ }^{(32,34-36)}$.

Sugar has long been known to play a major role in causing tooth decay ${ }^{(37)}$. In recent years a strong body of evidence has emerged that implicates sugar, especially when consumed as SSB, in several other disorders. The role of SSB in obesity was mentioned earlier. Several large cohort studies have reported that persons who have a relatively high consumption of SSB have an elevated risk of developing diabetes ${ }^{(38,39)}$ and $\mathrm{CHD}^{(40,41)}$.

\section{Mediterranean diet pattern}

The Mediterranean diet pattern has been the focus of considerable attention in recent years. This diet typically has a generous content of fruit, vegetables, whole-grain cereals, legumes, nuts, and includes fish and olive oil. Meat, especially red meat, is usually eaten in low amounts. Compared with a typical American diet the diet is rich in phytochemicals and fibre but low in saturated fat, haem iron and many other substances found in meat. A strong body of evidence has emerged from cohort studies and from RCT demonstrating that adherence to this diet is associated with a reduced risk of $\mathrm{CVD}^{(32)}$. Cohort studies indicate that the diet is protective against cancer ${ }^{(42)}$. It may also slow the rate of cognitive decline in older adults and help prevent Alzheimer's disease ${ }^{(43)}$

\section{Alcobol}

The harm caused by alcohol abuse is well known (chronic health and nutritional problems; accidents, violence and suicide; fetal alcohol syndrome). Alcohol intake is associated with an elevated risk for several types of cancer, including cancer of the colon, mouth and pharynx, oesophagus and liver ${ }^{(25,44)}$.

In contrast to these harmful effects, alcohol consumption in moderation is associated with numerous benefits, most notably a $30 \%$ reduced risk of $\mathrm{CHD}^{(45)}$. It must be emphasized that the relationship is U-shaped or J-shaped so that once alcohol consumption rises beyond the moderate range, there is a sharp jump in risk. Much the same relationship has been reported for several other disorders, including hypertension, stroke, type 2 diabetes, and decline in cognitive ability with ageing and the development of dementia ${ }^{(46)}$.

Alcohol consumption, therefore, has both multiple beneficial and harmful effects. In an estimate by Danaei et $a{ }^{(25)}$, alcohol causes 90000 deaths per annum in the USA but also prevents 26000 deaths. It therefore causes 64000 more deaths than it prevents. It is important to bear in mind that the harmful effects of alcohol frequently occur at a much younger age than the benefits. Accordingly, the people most likely to benefit from consuming alcohol are the middle-aged and elderly. This is particularly the case where intake is moderate (up to two drinks per day for men and one drink per day for women) and binge drinking is avoided.

\section{Dietary supplements}

A controversial area pertains to the use of dietary supplements. Supplements of iron and folic acid can be of value for many women during their reproductive years. Evidence has accumulated in recent years suggesting that vitamin D supplements may enhance resistance to bone fractures ${ }^{(47)}$ and to several diseases including CVD and cancer (especially colon cancer) ${ }^{(48,49)}$. While still controversial, the balance of evidence indicates that many people would benefit from a daily supplement providing at least $1000 \mathrm{IU}(25 \mu \mathrm{g})$ daily ${ }^{(49)}$. This is especially the case with the elderly, people with dark skin, those who expose little skin to the sun and for inhabitants of northern latitudes.

There has been much debate regarding whether healthy adults should take a one-a-day, multi-vitamin, multimineral supplement. Findings from several cohort studies demonstrate that persons who consume such supplements gain no benefit in terms of reduced all-cause mortality $^{(50-54)}$. This evidence as well as negative findings from several RCT leads to the conclusion that well-nourished adults should not consume these supplements ${ }^{(55)}$.

\section{Translating dietary advice}

Attention is now turned to the major strategies that are employed in efforts to transmit dietary advice to the general population, either directly or via health professionals.

\section{Dietary guidelines}

There are a variety of dietary guidelines that are aimed at the improvement of population diets. Some of these 
include quantitative recommendations; these are intended mainly for health professionals. One example is the Dietary Guidelines for Americans, published by the US Department of Agriculture ${ }^{(56)}$. Major recommendations include: saturated fat should be $<10 \%$ of energy; sodium $<2300 \mathrm{mg} / \mathrm{d}$ for half of the population, but $<1500 \mathrm{mg} / \mathrm{d}$ for children, adults aged $>50$ years and persons at risk; choose fibre-rich fruits, vegetables and whole grains often; and alcohol up to one drink per day for women and up to two per day for men.

Food-based dietary guidelines are an alternative type of dietary guidelines. These are based entirely on foods rather than nutrients, are non-quantitative and can be readily understood by the general public. These guidelines might include such statements as: eat lots of fruit and vegetables; eat more fish; and cut down on sugar.

Many countries have published food guides that provide advice on the overall diet for the general public. They tend to centre on a coloured diagram. They are, in essence, food-based dietary guidelines in a graphical format, often with the addition of the number of recommended servings from each food group. In 2011 the US Department of Agriculture published its latest food guide which comes in a simple pictorial design called MyPlate ${ }^{(57)}$. It is depicted as a plate with food sectors. Compared with MyPyramid, its predecessor, it gives very little attention to how many servings should be eaten from each food group and is much easier to understand. Other food guide designs are available ${ }^{(58-60)}$.

For each type of dietary guideline there have been major changes over the past 20 or 30 years, and there is a wide variation between countries. Unfortunately, there is a lack of hard evidence, based on sound research, as to what detailed content is most scientifically sound and which designs are most effective for conveying the message. One conclusion is inescapable: this entire field will be the scene of considerable debate, controversy and research for years to come.

\section{Food labels}

Foods sold in packages have both front-of-package (FOP) labels and back-of-package (BOP) labels. Their purpose is to inform consumers of the composition of foods and to facilitate the selection of a healthy diet. The focus here is on the food labels used in the USA and Canada, which are very similar in design. These labels fail to give consumers the required information in a user-friendly format ${ }^{(61)}$. The major problems are as follows:

- Many FOP labels give misleading names to foods. For example, several imitation juice products have names that suggest real fruit, such as fruit beverage and fruit cocktail.

- BOP labels give a rather confusing table with the content of selected food components (Nutrition Facts panel), but food components that should be consumed in limited amounts (such as sodium, sugar and saturated fat) are interspersed with others that are often lacking in the diet (such as dietary fibre and $n$-3 fatty acids).

- Serving sizes on food labels in the USA and Canada are different from the serving sizes used in each country's food guide. Furthermore, there are often inconsistencies in serving sizes for similar products, thereby making it difficult for consumers to compare them.

Not surprisingly, research studies reveal that most people are not able to properly comprehend the food labels used in the USA and Canada ${ }^{(62-64)}$. This prevents consumers from making informed choices as to which food items are healthiest.

In response to these problems, several alternative FOP food labelling systems have been developed. Numerous research studies have investigated which design features are most effective for assisting consumers in making a healthy food choice ${ }^{(65,66)}$. The system with the strongest supporting evidence is based on traffic lights. Coloured circles are placed on the FOP and indicate if the food has a high (red), medium (orange) or low (green) content of total fat, saturated fat, sugar and sodium ${ }^{(67)}$. The label also indicates the actual quantity of these substances per serving, as well as energy levels. The system has been widely adopted in the UK (where it was developed) and some other countries.

A useful addition to traffic lights labels is to add an extra traffic light to indicate the overall health value of the food $^{(68)}$. This would require a standardized methodology for comparison of diverse foods. Several such systems have been developed ${ }^{(69-71)}$.

As will be discussed later, it is almost certain that the food industry will vigorously oppose the implementation of a new food labelling system that includes a FOP label on many foods that implicitly states "unhealthy food, do not eat'.

\section{Health promotion}

Despite countless efforts to persuade the general public to follow expert advice, the American diet has hardly improved since $1970^{(72)}$. The 1970 s saw the first health promotion campaigns where the objective was to persuade sections of the population to adopt a healthier lifestyle, including an improved diet. Over the years many interventions have been carried out in the USA that attempted to persuade people to adopt a healthier lifestyle. The most common targets have been blood cholesterol, blood pressure, weight, tobacco use and exercise. Various methods have been used to reach the target population including the mass media and education through schools and supermarkets. In general, only limited success has been achieved by these efforts with only a small reduction in the estimated risk of $\mathrm{CHD}^{(73,74)}$.

While the results of these health promotion campaigns targeted at the general population have been mostly 
disappointing, some successes have been achieved ${ }^{(74)}$. An Australian intervention campaign in the 1990s used paid advertising with the aim of increasing consumption of fruit and vegetables. Consumption of fruit rose by $11 \%$ and vegetables by $17 \%^{(75)}$. By far the biggest success story came from North Karelia, a region of eastern Finland which had an exceptionally high rate of $\mathrm{CHD}^{(76)}$. The intervention included nutrition education as well as interventions aimed at other aspects of lifestyle. Between 1972, when the intervention began, and 2007, CHD mortality in middle-aged men fell by an astonishing $80 \%{ }^{(77)}$. An intensive educational campaign spread to the rest of Finland leading to a national drop in CHD rates.

Several other health promotion strategies have also been developed. Many interventions have been carried out in which people have been targeted at their worksite. This strategy can be highly cost-effective, saving employers several dollars for each dollar invested ${ }^{(78)}$. Offices of physicians have provided another venue for health promotion interventions. The major focus has been risk factors for CVD. Findings have been generally modest but useful $^{(79)}$. The Internet is an increasingly popular medium for health promotion. This is a diverse field with programmes targeting several areas of lifestyle including diet and obesity. Promising findings have been reported from many interventions ${ }^{(80)}$.

Looking at this area as a whole it is clear that most health promotion programmes have achieved, at best, only a modest degree of success. This might be expected to reduce the risk of CHD by about 5 to $15 \%$. While this is certainly of value in terms of population health, it will not, however, affect the majority of people. Despite this limited success health promotion can be a cost-effective way to educate and persuade large numbers of people to lead a healthier lifestyle and thereby improve their health ${ }^{(81,82)}$.

\section{Nutrition policy by governments for the prevention of disease}

The serious limitations of health promotion interventions stand in sharp contrast with the huge potential of nutrition policies implemented by governments. Here we examine several examples.

Refined cereals and foods with added sugar and fat are among the cheapest sources of energy (measured as dollars per $1000 \mathrm{~kJ}$ ). Such foods typically have a high energy density (energy per gram) but a low nutrient density (nutrient content per $100 \mathrm{~g}$ ). By contrast, nutrient-dense foods, such as fish, lean meat, vegetables and fruit, are generally far more expensive (as dollars per $1000 \mathrm{~kJ})^{(8,9)}$. Consequently less healthy diets are significantly cheaper than more healthy diets ${ }^{(83)}$. As a result, people with a low income are pressured to select less healthy diets with a relatively low content of several micronutrients (such as vitamin $\mathrm{C}$ and $\beta$-carotene) and a high energy density ${ }^{(84)}$. This helps explain why the poorest people are often the least healthy. It follows, therefore, that an adjustment to food prices has potential for improving diets.

In support of this argument there is much evidence indicating that manipulating food prices could shift consumption patterns in a healthier direction. This is based on the concept of 'price elasticity' (i.e. consumption falls in response to a rise in price and vice versa). Strong supporting evidence has come from studies on smoking and alcohol ${ }^{(85,86)}$. The effect is stronger among the lower socio-economic groups. What applies to tobacco and alcohol also applies to food ${ }^{(87,88)}$. Indeed, evidence demonstrates that when healthier foods are subsidized, there is an increase in the amounts sold $^{(88,89)}$. For example, a study in supermarkets in the Netherlands observed that a $50 \%$ cut in the price of fruit and vegetables brought about a substantial increase in purchases of these foods (approximately $124 \mathrm{~g}$ more per person per day) ${ }^{(90)}$. A detailed analysis across the USA concluded that as the price of fast food rises, children and adolescents eat more fruit and vegetables and a generally healthier $\operatorname{diet}^{(91)}$. Of particular importance, a $20 \%$ rise in the price of SSB will cause an estimated $24 \%$ decrease in consumption ${ }^{(92)}$.

Based on this evidence we can reasonably assume that the judicious use of taxes and subsidies can improve diets at a population level. For example, subsidies paid to milk producers could be changed to favour low-fat milk. It has been repeatedly asserted that a price hike on SSB would not only decrease consumption but also help counter obesity $^{(87,92-94)}$.

Another area that warrants a policy approach is food advertising on TV, especially when the target audience is children. About $80-90 \%$ of food advertising directed to children is for unhealthy food choices or for fast-food restaurants ${ }^{(95,96)}$. Unsurprisingly, children often respond by consuming more of the advertised foods ${ }^{(97,98)}$. This has been linked with the risk of overweight and obesity in children and adolescents ${ }^{(99)}$. A strong case can be made that society has a responsibility to protect children from TV advertising. It therefore makes good sense to implement regulations that ban advertising of unhealthy food products when the target audience is children. This has been done in several jurisdictions including Quebec (Canada), Sweden and Norway.

Government regulations could also be of enormous value in the area of food composition. As discussed earlier, the incidence of CVD could be much reduced by a sharp reduction in the dietary content of trans-fatty acids and salt. By far the most effective way to achieve this is by government action. Again, several jurisdictions have gone down this road. In late 2013 the US government announced its intention to adopt this policy.

In the case of salt, a widely supported strategy is to rely on voluntary action by the food industry. We can see the serious limitations with this strategy by looking at how it has worked in the $\mathrm{UK}^{(100)}$. Between 2001 and 2011 salt intake by adults in the UK fell by about $15 \%$ (a reduction 
in sodium from about 3700 to $3200 \mathrm{mg} / \mathrm{d}$ ). This is a greater fall than in any other country. However, the 2010 version of the Dietary Guidelines for Americans recommends a sodium intake for adults of $<2300 \mathrm{mg} / \mathrm{d}$, with a lower limit $(<1500 \mathrm{mg} / \mathrm{d}$ ) for the half of the population who are aged $>50$ years or at risk. The only practical way to achieve the lower target for half of all adults is to strive for that target for all adults. If other countries followed the voluntary strategy used in the UK and made progress at the same speed, it would take until around 2025 to 2040 to achieve the upper target for sodium intake $(2300 \mathrm{mg} / \mathrm{d})$, or until well beyond 2050 to achieve the lower target $(1500 \mathrm{mg} / \mathrm{d})$. That is clearly a feeble rate of progress. A far more sensible policy is for governments to mandate salt reduction using legislation ${ }^{(101)}$. By this means the targets could be achieved within a few years at minimal cost. There is probably no other policy that could have such an enormous beneficial impact on public health, so quickly and at so little cost.

There are many institutions that are under some degree of government control, such as schools, military bases, prisons and cafeterias in government offices. By means of regulations and incentives, these institutions could be required or encouraged to sell healthier meals while restricting the sale of less healthy foods. Government-run programmes, such as school meals and food assistance to the poor, are another potential vehicle by which a great many people could be encouraged to consume healthier foods ${ }^{(102)}$. Studies in both the $\mathrm{UK}^{(103)}$ and the USA ${ }^{(104)}$ reported an increased intake of fruit and vegetables when low-income women were given vouchers that could be exchanged for these foods.

The proposals looked at above are in the tradition of many decades of public health initiatives carried out by governments. One thinks of such measures as the provision of safe drinking-water, the removal of lead from gasoline, the addition of certain nutrients to foods to correct deficiencies, restrictions on smoking in public places and bans on advertising of tobacco products.

Unfortunately, only rarely have nutrition policies along these lines been implemented. While most governments issue food guides and other forms of dietary advice to their populations, there is often a disconnect from actual food policy. Typically, while the health arm of governments encourages people to eat a healthier diet, the departments responsible for the agricultural and food industries are mainly focused on maintaining high production and sales. We see this with the US government: it distributes billions of dollars as agricultural subsidies, much of it to growers of corn and soyabeans. A large part of these products are then used for the production of high-fructose corn syrup and for cattle feed. This results in a vast supply of relatively cheap SSB and burgers. However, there is little evidence that subsidies have a major effect on food prices ${ }^{(105,106)}$. The key problem here is that the subsidies are distributed for purely economic reasons, with little or no attempt to use these payments as a lever to improve the national diet. Adding to this problem such programmes as school meals and food assistance to the poor are often used by the US government as a convenient way to dispose of food surpluses rather than as an opportunity to improve the national diet.

One part of the world where government policy initiatives are actually being implemented is Latin America ${ }^{(107)}$. Governments in Mexico, Peru, Chile, Colombia, Costa Rica, Brazil, Uruguay and Ecuador have passed laws and implemented policies (or are in the process of doing so) designed to reduce the consumption of unhealthy foods, especially by children. Measures include improved food labelling, limiting the advertising directed to children for unhealthy foods and the sale of such foods in schools, and adding a tax to unhealthy foods.

\section{Campaigns against obesity}

Many policy experts have made policy proposals similar to those outlined above as a strategy to counter the obesity epidemic $^{(108)}$. This makes good sense as the basic cause of obesity, as discussed earlier in the present paper, is that the environment is obesogenic. A few campaigns using a broad strategy have been carried out and the outcomes indicate some success. In particular, two anti-obesity campaigns that had the goal of reducing the prevalence of obesity in children went well beyond a narrow health promotion approach and attempted to modify the obesogenic environment. In a campaign carried out in schools in two towns in France, children were given nutrition education as well as community activity in support of more physical activity and a healthier lifestyle ${ }^{(109)}$. At the same time there was much media interest. After 12 years, children aged 5-12 years in the intervention towns had a lower prevalence of overweight or obesity than those in two other towns that received no intervention $(7.4 \% v .19 \cdot 4 \%$ in boys; $10.4 \% v$. $16.0 \%$ in girls). This is a rare level of success.

A comparable intervention, called Romp \& Chomp, was conducted on young children in the city of Geelong, Australia $^{(110)}$. The goals were to reduce the prevalence of obesity by means of diet and exercise. The investigators summarize the radically changed environment as follows:

'Early-childhood settings in the intervention areas are now places in which fruit, vegetables, and water are promoted and packaged snacks and sweet drinks are restricted or discouraged. Driving these changes has been the implementation and enforcement of effective policy, cultural changes within organisations, and capacity-building with early-childhood teachers and caregivers. The consistency and continued reinforcement of messages across the community was a key factor in the success of the intervention...'

Over the course of 3 years the prevalence of overweight or obesity among children aged 3.5 years fell by $3.4 \%$ in the 
areas that received the intervention but by only $0.7 \%$ in the areas that received no intervention.

While the above two campaigns did succeed in modifying the obesogenic environment, this occurred to only a limited extent. Such factors as food prices and advertising on TV were beyond the control of the investigators. It seems reasonable to postulate that an anti-obesity campaign that went further in neutralizing the obesogenic environment would achieve even more success ${ }^{(111)}$.

\section{Issues of cost-effectiveness}

A critically important aspect of disease prevention is costeffectiveness. It is often assumed that disease prevention saves money as it reduces health-care spending, but this is often not the case. In actuality, most medical interventions designed to prevent disease or improve health cause an increase in health-care spending ${ }^{(112,113)}$. By contrast, many of the proposals made above for using a government policy approach to disease prevention can - potentially have a major impact at relatively small cost. Accordingly, such a strategy should be highly cost-effective as the following examples illustrate:

- Implementing a policy to reduce the salt content of many foods would cost very little and, as stated earlier, would most probably prevent many thousands of cases of CVD.

- Similarly, a policy that mandated the removal of transfatty acids from foods is projected to prevent thousands of deaths from CHD each year. According to a 2003 estimate, there would be a one-time industry cost in the USA of \$US 139 million to \$US 275 million $^{(114)}$.

- Changes to food prices by means of taxes and subsidies may be quite high in the short term due to disruptions in patterns of agriculture and food production. However, in the longer term the cost should be minimal as extra costs in one area are cancelled out by savings in other areas.

We can reasonably assume, therefore, that a government policy approach to disease prevention is far more costeffective than a medical approach. This was confirmed in a recent study which reported that $46 \%$ of interventions that prevent disease by 'changing the environment' are cost saving, but this occurs with only $16 \%$ of diseasepreventing clinical interventions, such as cancer screening and drug treatment for hypertension ${ }^{(108)}$.

\section{Opposition from food corporations}

In the USA and other countries the food industry spends lavishly to protect and foster its interests. There are many lobbyists in Washington, DC working on behalf of food corporations. This is the likely reason why government policies in the USA often appear to be designed to protect the interests of food corporations rather than the health of the American population ${ }^{(115,116)}$. There is good reason to believe that a similar story has been unfolding in Canada ${ }^{(117)}$. This explains why successive governments of both countries have avoided all policy actions that might significantly reduce consumption of unhealthy foods. For example, there has been minimal action to introduce effective FOP food labels, to add a tax on SSB or to lower the salt content of foods. Instead, governments have used much weaker tools, such as food guides. It appears, therefore, that food industry lobbyists have successfully thwarted all serious attempts to introduce truly effective policies at the federal level for improving the diets of each country. While policy developments at the federal level have been painstakingly slow, many valuable actions have taken place at the state and local level in the USA, such as improvements in the school food environment and the imposition of modest taxes on SSB.

This problem is also seen in other parts of the world. In 2010 the European Parliament debated the adoption of traffic lights food labels, a policy opposed by the food industry. The industry carried out massive lobbying, spending an estimated 1 billion $€$ (\$US 1.3 billion) in a successful attempt to defeat the proposed law ${ }^{(118,119)}$. Australia provides a similar example. In 2006 the food industry in that country introduced a voluntary system for FOP food labels. The apparent motive had less to do with informing consumers and more to do with the avoidance of a government-implemented system. A survey conducted in 2012 revealed that the food industry was routinely ignoring key parts of its own code of practice, namely by not stating the quantity of saturated fat and sugar in energy-dense, nutrient-poor snacks (i.e. the foods where these labels are most needed) ${ }^{(120)}$. At the same time the food industry strongly opposed government initiatives to implement a compulsory FOP labelling scheme ${ }^{(121)}$.

A strategy that has been used in different countries in an effort to make diets healthier is voluntary agreements with the food industry. Some examples of this have been mentioned in the present paper, including the UK strategy for salt reduction and the FOP food labelling scheme in Australia. The Lancet NCD Action Group recently made the argument that this approach generally achieves little success as the food industry is primarily interested in boosting its profits rather than making diets healthier ${ }^{(122)}$. These authors argue that government regulation is the one effective means to control the consumption of highly processed foods.

\section{The problem of false and misleading nutrition information}

While many agencies strive to achieve a positive impact on the national diet by way of such tools as food guides, food labels and the education of schoolchildren, other folk work with as much energy to achieve the opposite.

Approximately one-third of adult Americans use vitamin/ mineral supplements and about $20 \%$ take herbal supplements ${ }^{(123)}$. In total about half of all Americans take a 
dietary supplement regularly. Unfortunately, a close examination of the marketing of dietary supplements reveals a situation where the dominant objective is to maximize sales and profits, while honesty has been relegated to a minor role ${ }^{(124)}$.

There are several thousand health food stores across North America. They sell a wide variety of dietary supplements. In recent years most pharmacies and supermarkets have given over much shelf space to supplements. Several studies have reported that when customers request advice from staff in health food stores, they are typically given advice that has little or no supporting scientific evidence ${ }^{(125)}$. Dishonest marketing of supplements is also commonly done through advertisements in newspapers and magazines. Readers wishing to buy supplements are then directed to either health food stores or Internet websites.

The general public needs to be informed of these problems. In particular, it should be told to ignore advertisements for dietary supplements and not to listen to sales staff in health food stores. Instead, when people want advice they should only use credible sources of information.

With respect to the USA a major reason for this sorrowful state of affairs is because of the weakness of the law. Supplements are regulated by the Dietary Supplement and Health Education Act of 1994. This law allows those engaged in the manufacture or selling of supplements to act in an unscrupulous manner with little risk of government intervention. For example, they can make practically any claim they want for the health benefits of their products.

The previous section referred to the problem of corporations using their lobbying power to influence laws and policies within the USA. The Dietary Supplement and Health Education Act is an excellent example of this: the law was passed after the supplement industry exerted intense pressure on Congress ${ }^{(115)}$.

Quite apart from the marketing of dietary supplements of dubious value, there are other important ways by which the public is fed misinformation. Books are one important area.

The following is an especially egregious example. Dozens of books have been published based on the bogus concept that a person's blood type plays an important role in explaining health problems and that people should choose what foods to eat based on their blood type. Similarly, hundreds of books are published each year that promise quick and easy weight loss. Many of the authors appear to have no relevant qualifications while many others have 'MD' after their names. As these books contradict each other, only a tiny number of them, at most, can be right. This problem extends to magazines. For example, Woman's World is a supermarket tabloid sold across North America that regularly displays the latest 'lose a pound per day' diet on its front cover.

\section{Summary of key challenges in public health nutrition}

The world of nutrition is like a river: many streams can merge into a major river of thought and action. Over the last two decades several new streams have merged with the river. The present paper has covered diverse areas and has presented many individual items of information and analysis. More extensive reviews have been published elsewhere $^{(105)}$.

The key points are as follows:

1. Reduce consumption of unhealthy foods. This includes SSB and those foods that are energy dense but with a low nutrient density, such as foods with a high content of fat or sugar and refined cereal products.

2. Increase consumption of fruit, vegetables, whole grains and fish.

3. Reduce the dietary content of salt and trans-fatty acids.

4. Avoid excessive drinking of alcohol, especially binge drinking. However, drinking alcohol in moderation may be healthy, especially for the middle-aged and elderly.

5. Well-nourished adults should not consume multivitamin supplements.

6. Continuous work is required to improve the quality and effectiveness of food guides and food labels.

7. Health promotion campaigns need to be expanded based on lessons learned from previous campaigns.

8. Of particular importance is government policy action in such areas as developing laws and regulations (e.g. strict limitations on the content of salt and trans-fatty acids in foods and on the advertising of unhealthy foods on children's TV programmes) and the use of taxes and subsidies to encourage better population nutrition.

9. A major goal is to create an environment that supports healthy choices in diet and other aspects of lifestyle. Countering the obesogenic environment is of particular importance.

10. These actions need to be done cost-effectively.

11. There must be resistance against efforts by corporations to sabotage these actions.

12. The public needs more and better education on issues related to diet.

\section{Strategic nutrition}

The time has now arrived for the development of an overall strategy based on the above key points; we need an action plan for public health nutrition. I propose the term 'strategic nutrition'. The ten key elements are as follows:

1. Regular publication of reviews in key areas. The preferred method is by systematic reviews and metaanalyses. However, the evidence in an area is often 
contradictory and requires complex interpretation. Examples include vitamin $\mathrm{D}$ in cancer, alcohol in CHD, and dietary advice for achieving weight control. In such cases what is generally most appropriate is a consensus statement that summarizes the contradictory viewpoints and presents a balanced overall judgement.

2. Translation of this information into advice for the general population. This includes the release of information to the media and ensuring that health professionals are providing the most up-to-date information. A major challenge in this area is that the public is exposed to vast amounts of distorted information that comes in various forms, such as TV adverts, magazines and books. Those striving to deliver accurate information often seem to be blowing against the wind. Arguably, the best solution is a well-funded agency that provides accurate information on nutrition and achieves a high profile.

3. There is a need for more research on the most effective content and design of food guides, foodbased dietary guidelines and food labels.

4. The stricter regulation of adverts for unhealthy foods, especially when the target audience is children.

5. Providing advice to governments on the formulation of nutrition policy. Priority areas include: (i) setting standards for the content of sodium and trans-fatty acids in foods; and (ii) the development of food labels that have a user-friendly design and encourage consumers to select healthier foods.

6. Governments need to fundamentally change the way that food subsidies are distributed. At present they are part of the problem. A new system is required based on the principle that the health of the general population is the top priority. This could include some combination of subsidies to encourage consumption of healthier foods, such as fruit and vegetables, and taxes on less healthy products.

7. By means of regulations and incentives, institutions that are under some degree of government control, such as schools, military bases and cafeterias in government offices, should be required or encouraged to sell meals of superior health value while restricting the sale of less healthy foods. Similarly, programmes involved in giving food assistance to people on low incomes could be mandated to provide healthier foods where feasible.

8. Health promotion interventions are much less effective than nutrition policies implemented by governments. Nevertheless, they still have much value. It may be time to consider a new class of health professional who specializes in delivering health promotion. The person would be trained in nutrition, exercise, behaviour modification and related areas, such as techniques to help people quit smoking. The practitioner of health promotion would work in such settings as schools, workplaces, gyms and senior centres.
9. There are serious problems seen with the marketing of dietary supplements. Only a few supplements are of proven value. There is a vital need for stricter regulation, including greater supervision of the industry by government agencies. Specifically, there must be action to curb the blatantly dishonest marketing of supplements. There is also a need for routine checks on the actual composition of supplements. Additionally, consumers should be provided with better education concerning the issues around supplements.

10. Ideally, implementation of this action plan for strategic nutrition should be carried out by a single government agency based in the department of health. Specific policies will be formulated based on scientific evidence both of effectiveness and of cost-effectiveness. However, before that stage is reached many of the proposals made above require action by different government departments. Others will require legislation. The details as to how this must be done will, of course, vary from country to country.

The implementation of an action plan based on strategic nutrition opens up a path to a major advance in public health. However, there are serious obstacles. In particular, it is highly likely that some food corporations will see aspects of the proposed strategy as a possible threat to their profits. They will probably respond by lobbying the government in order to thwart proposed changes. Any such lobbying must be resisted vigorously.

\section{Acknowledgements}

Financial support: This work received no specific grant from any funding agency in the public, commercial or not-for-profit sectors. Conflict of interest: None. Ethics of buman subject participation: Ethical approval was not required.

\section{References}

1. Malik VS, Pan A, Willett WC et al. (2013) Sugar-sweetened beverages and weight gain in children and adults: a systematic review and meta-analysis. Am J Clin Nutr 98, 1084-1102.

2. Forouhi NG, Sharp SJ, Du H et al. (2009) Dietary fat intake and subsequent weight change in adults: results from the European Prospective Investigation into Cancer and Nutrition cohorts. Am J Clin Nutr 90, 1632-1641.

3. Hooper L, Abdelhamid A, Moore HJ et al. (2012) Effect of reducing total fat intake on body weight: systematic review and meta-analysis of randomised controlled trials and cohort studies. BMJ 345, e7666.

4. Pérez-Escamilla R, Obbagy JE, Altman JM et al. (2012) Dietary energy density and body weight in adults and children: a systematic review. J Acad Nutr Diet 112, 671-684.

5. Rolls BJ (2009) The relationship between dietary energy density and energy intake. Physiol Behav 97, 609-615.

6. Rolls BJ (2003) The supersizing of America: portion size and the obesity epidemic. Nutr Today 38, 42-53. 
7. Young LR \& Nestle M (2012) Reducing portion sizes to prevent obesity: a call to action. Am J Prev Med 43, 565-568.

8. Drewnowski A \& Darmon N (2005) Food choices and diet costs: an economic analysis. J Nutr 135, 900-904.

9. Drewnowski A, Monsivais P, Maillot M et al. (2007) Lowenergy-density diets are associated with higher diet quality and higher diet costs in French adults. I Am Diet Assoc 107, 1028-1032.

10. $\quad$ Burger $\beta$ usiness (2011) Restaurant Ad Spending Tops $\$ 5.6$ Billion in 2010. http://www.burgerbusiness.com/?p=6925 (accessed July 2011).

11. Advertising Age (2010) 100 Leading National Advertisers: 2010 Report. http://adage.com/datacenter/marketertrees 2010 (accessed June 2011).

12. Kann L, Kinchen S, Shanklin SL et al.; Centers for Disease Control and Prevention (2014) Youth risk behavior surveillance - United States, 2013. MMWR Surveill Summ 63 , Suppl. 4, 1-168.

13. Schulze MB, Schulz M, Heidemann C et al. (2007) Fiber and magnesium intake and incidence of type 2 diabetes: a prospective study and meta-analysis. Arch Intern Med 167, 956-965.

14. Schellenberg ES, Dryden DM, Vandermeer B et al. (2013) Lifestyle interventions for patients with and at risk for type 2 diabetes: a systematic review and meta-analysis. Ann Intern Med 159, 543-551.

15. Willett WC (2012) Dietary fats and coronary heart disease. J Intern Med 272, 13-24.

16. Mozaffarian D, Micha R \& Wallace S (2010) Effects on coronary heart disease of increasing polyunsaturated fat in place of saturated fat: a systematic review and metaanalysis of randomized controlled trials. PLoS Med 7, e1000252.

17. Hoenselaar R (2012) Saturated fat and cardiovascular disease: the discrepancy between the scientific literature and dietary advice. Nutrition 28, 118-123.

18. Ramsden CE, Zamora D, Leelarthaepin B et al. (2013) Use of dietary linoleic acid for secondary prevention of coronary heart disease and death: evaluation of recovered data from the Sydney Diet Heart Study and updated metaanalysis. BMJ 346, e8707.

19. Siri-Tarino PW, Sun Q, Hu FB et al. (2010) Meta-analysis of prospective cohort studies evaluating the association of saturated fat with cardiovascular disease. Am J Clin Nutr 91, 535-546.

20. Stamler J (2010) Diet-heart: a problematic revisit. Am J Clin Nutr 91, 497-499.

21. Zheng J, Huang T, Yu Y et al. (2012) Fish consumption and CHD mortality: an updated meta-analysis of seventeen cohort studies. Public Health Nutr 15, 725-737.

22. Mozaffarian D \& Wu JH (2011) Omega-3 fatty acids and cardiovascular disease: effects on risk factors, molecular pathways, and clinical events. $J$ Am Coll Cardiol 58, 2047-2067.

23. Rizos EC, Ntzani EE, Bika E et al. (2012) Association between omega-3 fatty acid supplementation and risk of major cardiovascular disease events: a systematic review and meta-analysis. JAMA 308, 1024-1033.

24. Mozaffarian D, Katan MB, Ascherio A et al. (2006) Trans fatty acids and cardiovascular disease. $N$ Engl J Med 354, 1601-1613.

25. Danaei G, Ding EL, Mozaffarian D et al. (2009) The preventable causes of death in the United States: comparative risk assessment of dietary, lifestyle, and metabolic risk factors. PLoS Med 6, e1000058.

26. Aburto NJ, Ziolkovska A, Hooper L et al. (2013) Effect of lower sodium intake on health: systematic review and meta-analyses. BMJ 346, f1326.

27. He FJ, Li J \& Macgregor GA (2013) Effect of longer term modest salt reduction on blood pressure: Cochrane systematic review and meta-analysis of randomised trials. BMJ 346, f1325.

28. Bibbins-Domingo $\mathrm{K}$, Chertow GM, Coxson PG et al. (2010) Projected effect of dietary salt reductions on future cardiovascular disease. $N$ Engl I Med 362 , 590-599.

29. Riboli E \& Norat T (2003) Epidemiologic evidence of the protective effect of fruit and vegetables on cancer risk. Am J Clin Nutr 78, 3 Suppl., 559S-569S.

30. Boffetta P, Couto E, Wichmann J et al. (2010) Fruit and vegetable intake and overall cancer risk in the European Prospective Investigation into Cancer and Nutrition (EPIC). I Natl Cancer Inst 102, 529-537.

31. Hung HC, Joshipura KJ, Jiang R et al. (2004) Fruit and vegetable intake and risk of major chronic disease. $J$ Natl Cancer Inst 96, 1577-1584.

32. Mozaffarian D, Appel LJ \& Van Horn L (2011) Components of a cardioprotective diet: new insights. Circulation 123 , 2870-2891.

33. Aune D, Chan DS, Lau R et al. (2011) Dietary fibre, whole grains, and risk of colorectal cancer: systematic review and dose-response meta-analysis of prospective studies. BMJ 343, d6617.

34. Pan A, Sun Q, Bernstein AM et al. (2012) Red meat consumption and mortality: results from 2 prospective cohort studies. Arch Intern Med 172, 555-563.

35. Rohrmann S, Overvad K, Bueno-de-Mesquita $\mathrm{HB}$ et al. (2013) Meat consumption and mortality - results from the European Prospective Investigation into Cancer and Nutrition. BMC Med 11, 63.

36. Sinha R, Cross AJ, Graubard BI et al. (2009) Meat intake and mortality: a prospective study of over half a million people. Arch Intern Med 169, 562-571.

37. Moynihan P \& Petersen PE (2004) Diet, nutrition and the prevention of dental diseases. Public Health Nutr 7 , 201-226.

38. Malik VS, Popkin BM, Bray GA et al. (2010) Sugarsweetened beverages and risk of metabolic syndrome and type 2 diabetes: a meta-analysis. Diabetes Care 33 , 2477-2483.

39. de Koning L, Malik VS, Rimm EB et al. (2011) Sugarsweetened and artificially sweetened beverage consumption and risk of type 2 diabetes in men. Am J Clin Nutr $\mathbf{9 3}$, 1321-1327.

40. Fung TT, Malik V, Rexrode KM et al. (2009) Sweetened beverage consumption and risk of coronary heart disease in women. Am J Clin Nutr 89, 1037-1042.

41. de Koning L, Malik VS, Kellogg MD et al. (2012) Sweetened beverage consumption, incident coronary heart disease, and biomarkers of risk in men. Circulation $\mathbf{1 2 5}$, 1735-1741

42. Sofi F, Abbate R, Gensini GF et al. (2010) Accruing evidence on benefits of adherence to the Mediterranean diet on health: an updated systematic review and metaanalysis. Am J Clin Nutr 92, 1189-1196.

43. Lourida I, Soni M, Thompson-Coon J et al. (2013) Mediterranean diet, cognitive function, and dementia: a systematic review. Epidemiology 24, 479-489.

44. Bagnardi V, Blangiardo M, Vecchia CL et al. (2001) A meta-analysis of alcohol drinking and cancer risk. $\mathrm{Br} \mathrm{J}$ Cancer 85, 1700-1705.

45. Ronksley PE, Brien SE, Turner BJ et al. (2011) Association of alcohol consumption with selected cardiovascular disease outcomes: a systematic review and meta-analysis. BMJ 342, d671.

46. Temple NJ (2012) What are the health implications of alcohol consumption? In Nutritional Health: Strategies for Disease Prevention, 3rd ed., pp. 323-334 [NJ Temple, $\mathrm{T}$ Wilson and DR Jacobs, editors]. New York: Humana Press. 
47. Bischoff-Ferrari HA, Willett WC, Orav EJ et al. (2012) A pooled analysis of vitamin D dose requirements for fracture prevention. $N$ Engl J Med 367, 40-49.

48. Scragg R (2011) Vitamin D and public health: an overview of recent research on common diseases and mortality in adulthood. Public Health Nutr 14, 1515-1532.

49. Chowdhury R, Kunutsor S, Vitezova A et al. (2014) Vitamin D and risk of cause specific death: systematic review and meta-analysis of observational cohort and randomised intervention studies. BMJ 348, g1903.

50. Watkins ML, Erickson JD, Thun MJ et al. (2000) Multivitamin use and mortality in a large prospective study. $\mathrm{Am}$ J Epidemiol 152, 149-162.

51. Neuhouser ML, Wassertheil-Smoller S, Thomson C et al. (2009) Multivitamin use and risk of cancer and cardiovascular disease in the Women's Health Initiative cohorts. Arch Intern Med 169, 294-304.

52. Pocobelli G, Peters U, Kristal AR et al. (2009) Use of supplements of multivitamins, vitamin $\mathrm{C}$, and vitamin $\mathrm{E}$ in relation to mortality. Am J Epidemiol 170, 472-483.

53. Mursu J, Robien K, Harnack LJ et al. (2011) Dietary supplements and mortality in older women: the Iowa Women's Health Study. Arch Intern Med 171, 1625-1633.

54. Park SY, Murphy SP, Wilkens LR et al. (2011) Multivitamin use and the risk of mortality and cancer incidence: the multiethnic cohort study. Am J Epidemiol 173, 906-914.

55. Guallar E, Stranges S, Mulrow C et al. (2013) Enough is enough: stop wasting money on vitamin and mineral supplements. Ann Intern Med 159, 850-851.

56. US Department of Agriculture (2010) Dietary Guidelines for Americans, 2010. http://www.cnpp.usda.gov/DGAs 2010-PolicyDocument.htm (accessed May 2013).

57. US Department of Agriculture (2011) MyPlate. http:// www.choosemyplate.gov (accessed May 2013).

58. Department of Nutrition, Harvard School of Public Health (2013) The Nutrition Source. http://www.thenutrition source.org (accessed May 2013).

59. Health Canada (2011) Eating Well with Canada's Food Guide. http://hc-sc.gc.ca/fn-an/food-guide-aliment/indexeng.php (accessed January 2015).

60. Temple NJ \& Bourne LT (2010) A proposed new food guide: why pyramids should stop at traffic lights. Ethn Dis 20, 485-487.

61. Temple NJ \& Fraser J (2014) Food labels: a critical assessment. Nutrition 30, 257-260.

62. Ollberding NJ, Wolf RL \& Contento I (2010) Food label use and its relation to dietary intake among US adults. $J \mathrm{Am}$ Diet Assoc 110, 233-237.

63. Cowburn G \& Stockley L (2005) Consumer understanding and use of nutrition labelling: a systematic review. Public Health Nutr 8, 21-28.

64. Vanderlee L, Goodman S, Yang Ws et al. (2012) Consumer understanding of calorie amounts and serving size: implications for nutritional labeling. Can J Public Health 103, e327.

65. Hersey JC, Wohlgenant KC, Arsenault JE et al. (2013) Effects of front-of-package and shelf nutrition labeling systems on consumers. Nutr Rev 71, 1-14.

66. Hawley KL, Roberto CA, Bragg MA et al. (2013) The science on front-of-package food labels. Public Health Nutr 16, 430-439.

67. Food Standards Agency (2007) Front of pack traffic light signpost labelling. Technical guidance. http://www.food. gov.uk/multimedia/pdfs/frontofpackguidance2.pdf (accessed June 2013).

68. Temple NJ (2014) Re: Food labels: a critical assessment. Nutrition 30, 1217-1218.

69. Sacks G, Rayner M, Stockley L et al. (2011) Applications of nutrient profiling: potential role in diet-related chronic disease prevention and the feasibility of a core nutrientprofiling system. Eur J Clin Nutr 65, 298-306.

70. NuValTM (2013) Nutritional scoring system. http://www. nuval.com (accessed May 2013).

71. Chiuve SE, Sampson L \& Willett WC (2011) The association between a nutritional quality index and risk of chronic disease. Am J Prev Med 40, 505-513.

72. Krebs-Smith SM, Reedy J \& Bosire C (2010) Healthfulness of the US food supply: little improvement despite decades of dietary guidance. Am J Prev Med 38, 472-477.

73. Winkleby MA, Feldman HA \& Murray DM (1997) Joint analysis of three US community intervention trials for reduction of cardiovascular risk. J Clin Epidemiol 50, 645-658.

74. Temple NJ \& Nestle M (2012) Population nutrition and health promotion. In Nutritional Health: Strategies for Disease Prevention, 3rd ed., pp. 373-390 [NJ Temple, T Wilson and DR Jacobs, editors]. New York: Humana Press.

75. Dixon H, Boland R, Segan C et al. (1998) Public reaction to Victoria's '2 Fruit ' $n$ ' 5 Veg Every Day' campaign and reported consumption of fruit and vegetables. Prev Med 27, 572-582.

76. Puska P, Nissinen A, Tuomilehto J et al. (1985) The community based strategy to prevent coronary heart disease: conclusions from the ten years of North Karelia project. Annu Rev Public Health 6, 147-193.

77. Vartiainen E, Laatikainen T, Peltonen M et al. (2010) Thirty-five-year trends in cardiovascular risk factors in Finland. Int J Epidemiol 39, 504-518.

78. Carnethon M, Whitsel LP, Franklin BA et al. (2009) Worksite wellness programs for cardiovascular disease prevention: a policy statement from the American Heart Association. Circulation 120, 1725-1741.

79. Wilcox S, Parra-Medina D, Thompson-Robinson M et al. (2001) Nutrition and physical activity interventions to reduce cardiovascular disease risk in health care settings: a quantitative review with a focus on women. Nutr Rev 59, 197-214.

80. Krebs P, Prochaska JO \& Rossi JS (2010) A meta-analysis of computer-tailored interventions for health behavior change. Prev Med 51, 214-121.

81. Aldana SG (2001) Financial impact of health promotion programs: a comprehensive review of the literature. $\mathrm{Am} \mathrm{J}$ Health Promot 15, 296-320.

82. Golaszewski T (2001) Shining lights: studies that have most influenced the understanding of health promotion's financial impact. Am J Health Promot 15, 332-340.

83. Rao M, Afshin A, Singh G et al. (2013) Do healthier foods and diet patterns cost more than less healthy options? A systematic review and meta-analysis. BMJ Open $\mathbf{3}$, $\mathrm{e} 004277$.

84. Darmon N \& Drewnowski A (2008) Does social class predict diet quality? Am J Clin Nutr 87, 1107-1117.

85. Meier KJ \& Licari MJ (1997) The effect of cigarette taxes on cigarette consumption, 1955 through 1994. Am J Public Health 87, 1126-1130.

86. Anderson P, Chisholm D \& Fuhr DC (2009) Effectiveness and cost-effectiveness of policies and programmes to reduce the harm caused by alcohol. Lancet 373, 2234-2246.

87. Andreyeva T, Long MW \& Brownell KD (2010) The impact of food prices on consumption: a systematic review of research on the price elasticity of demand for food. $A m J$ Public Health 100, 216-222.

88. Thow AM, Downs S \& Jan S (2014) A systematic review of the effectiveness of food taxes and subsidies to improve diets: understanding the recent evidence. Nutr Rev $\mathbf{7 2}$, 551-565.

89. An R (2013) Effectiveness of subsidies in promoting healthy food purchases and consumption: a review of field experiments. Public Health Nutr 16, 1215-1228. 
90. Waterlander WE, de Boer MR, Schuit AJ et al. (2013) Price discounts significantly enhance fruit and vegetable purchases when combined with nutrition education: a randomized controlled supermarket trial. Am J Clin Nutr 97, 886-895.

91. Beydoun MA, Powell LM, Chen X et al. (2011) Food prices are associated with dietary quality, fast food consumption, and body mass index among US children and adolescents. J Nutr 141, 304-311.

92. Powell LM, Chriqui JF, Khan T et al. (2013) Assessing the potential effectiveness of food and beverage taxes and subsidies for improving public health: a systematic review of prices, demand and body weight outcomes. Obes Rev 14, 110-128.

93. Andreyeva T, Chaloupka FJ \& Brownell KD (2011) Estimating the potential of taxes on sugar-sweetened beverages to reduce consumption and generate revenue. Prev Med 52, 413-416.

94. Powell LM \& Chaloupka FJ (2009) Food prices and obesity: evidence and policy implications for taxes and subsidies. Milbank Q 87, 229-257.

95. Harrison K \& Marske AL (2005) Nutritional content of foods advertised during the television programs children watch most. Am J Public Health 95, 1568-1574.

96. Batada A, Seitz MD, Wootan MG et al. (2008) Nine out of 10 food advertisements shown during Saturday morning children's television programming are for foods high in fat, sodium, or added sugars, or low in nutrients. J Am Diet Assoc 108, 673-678.

97. Coon KA \& Tucker KL (2002) Television and children's consumption patterns. A review of the literature. Minerva Pediatr 54, 423-436.

98. Wiecha JL, Peterson KE, Ludwig DS et al. (2006) When children eat what they watch: impact of television viewing on dietary intake in youth. Arch Pediatr Adolesc Med $\mathbf{1 6 0}$, 436-442.

99. Chou S, Rashad I \& Grossman M (2008) Fast-food restaurant advertising on television and its influence on childhood obesity. J Law Econ 51, 599-618.

100. Brinsden HC, He FJ, Jenner KH et al. (2013) Surveys of the salt content in UK bread: progress made and further reductions possible. BMJ Open 3, e002936.

101. Temple NJ (2011) Population strategies to reduce sodium intake: the right way and the wrong way. Nutrition $\mathbf{2 7}$, 387.

102. Finkelstein DM, French S, Variyam JN et al. (2004) Pros and cons of proposed interventions to promote healthy eating. Am J Prev Med 27, 3 Suppl., 163-171.

103. Burr ML, Trembeth J, Jones KB et al. (2007) The effects of dietary advice and vouchers on the intake of fruit and fruit juice by pregnant women in a deprived area: a controlled trial. Public Health Nutr 10, 559-565.

104. Herman DR, Harrison GG \& Jenks E (2006) Choices made by low-income women provided with an economic supplement for fresh fruit and vegetable purchase. J Am Diet Assoc 106, 740-744.

105. Mozaffarian D, Afshin A, Benowitz NL et al. (2012) Population approaches to improve diet, physical activity, and smoking habits: a scientific statement from the American Heart Association. Circulation 126, 1514-1563.

106. Rickard BJ, Okrent AM \& Alston JM (2013) How have agricultural policies influenced caloric consumption in the United States? Health Econ 22, 316-339.
107. Fraser B (2013) Latin American countries crack down on junk food. Lancet 382, 385-386.

108. Nestle M \& Jacobson MF (2000) Halting the obesity epidemic: a public health policy approach. Public Health Rep 115, 12-24.

109. Romon M, Lommez A, Tafflet M et al. (2009) Downward trends in the prevalence of childhood overweight in the setting of 12-year school- and community-based programmes. Public Health Nutr 12, 1735-1742.

110. de Silva-Sanigorski AM, Bell AC, Kremer P et al. (2010) Reducing obesity in early childhood: results from Romp \& Chomp, an Australian community-wide intervention program. Am J Clin Nutr 91, 831-840.

111. Foresight (2007) Tackling obesities: future choices. http:// www.bis.gov.uk/foresight (accessed May 2013).

112. Cohen JT, Neumann PJ \& Weinstein MC (2008) Does preventive care save money? Health economics and the presidential candidates. $N$ Engl J Med 358, 661-663.

113. Chokshi DA \& Farley TA (2012) The cost-effectiveness of environmental approaches to disease prevention. $N$ Engl J Med 367, 295-297.

114. US Department of Health and Human Services (2003) Food labeling: trans fatty acids in nutrition labeling, nutrient content claims, and health claims, Final Rule. Fed Reg 68, 41434-41506.

115. Nestle M (2007) Food Politics: How the Food Industry Influences Nutrition and Health. Berkeley, CA: University of California Press.

116. Nestle M \& Wilson T (2013) Food industry and political influences on American nutrition. In Nutritional Health: Strategies for Disease Prevention, 3rd ed., pp. 477-490 [NJ Temple, T Wilson and DR Jacobs, editors]. New York: Humana Press.

117. Campbell N, Willis KJ, Gavin A et al. (2013) Federal government food policy committees and the financial interests of the food sector. Open Med 7, 107-111.

118. Hickman M (2010) Laid bare, the lobbying campaign that won the food labelling battle. The Independent, 18 June. http://www.independent.co.uk/life-style/food-and-drink/ news/laid-bare-the-lobbying-campaign-thatwon-the-foodlabelling-battle-2003686.html (accessed December 2013).

119. Anon. (2010) Food industry wins battle on 'traffic light' labels. EurActiv, 17 June. http://www.euractiv.com/foodindustry-wins-battle-traffic-light-labels-news-495324 (accessed December 2013)

120. Carter OB, Mills BW, Lloyd E et al. (2013) An independent audit of the Australian food industry's voluntary front-ofpack nutrition labelling scheme for energy-dense nutritionpoor foods. Eur J Clin Nutr 67, 31-35.

121. Magnusson RS (2010) Obesity prevention and personal responsibility: the case of front-of-pack food labelling in Australia. BMC Public Health 10, 662.

122. Moodie R, Stuckler D, Monteiro C et al. (2013) Profits and pandemics: prevention of harmful effects of tobacco, alcohol, and ultra-processed food and drink industries. Lancet 381, 670-679.

123. Bailey RL, Gahche JJ, Lentino CV et al. (2011) Dietary supplement use in the United States, 2003-2006. J Nutr 141, 261-266.

124. Temple NJ (2013) The marketing of dietary supplements: a Canadian perspective. Curr Nutr Rep 2, 167-173.

125. Temple NJ, Eley D \& Nowrouzi B (2009) Advice on dietary supplements: a comparison of health food stores and pharmacies in Canada. J Am Coll Nutr 28, 674-677. 